\title{
EPIDEMIOLOGY OF SPORTS INJURIES ON COLLEGIATE ATHLETES AT A SINGLE CENTER
}

\author{
Bruno Berbert Rosa ${ }^{1}$, André Marangoni Asperti ${ }^{1}$, Camilo Partezani Helito ${ }^{1}$, Marco Kawamura Demange ${ }^{1}$, \\ Tiago Lazzaretti Fernandes ${ }^{1}$, Arnaldo José Hernandez ${ }^{1}$
}

\begin{abstract}
Objective: To evaluate the incidence of sports injuries in college athletes from the same institution from 1993 to 2013. Methods: Athletes from 13 modalities were interviewed about the presence and type of injury, type of treatment and time of withdrawal, based on the questionnaire "Injury Surveillance System" (ISS). Data were analyzed with graphs and tables of injury prevalence by gender, age, site of injury and modality. We also analyzed the average time of withdrawal of athletes, returning to sports practice and new lesions. Results: It was observed that $49.91 \%$ of the athletes showed some type of injury, with similar incidence between genders; the most frequent injuries were the
\end{abstract}

anterior cruciate ligament (ACL) and the ankle sprain; the average withdrawal time was 11 weeks. $A C L$ was the injury with greater impact on college sports career, especially given the time of withdrawal. Conclusion: The most frequent injury, ACL, occurred most frequently in indoor sports such as handball and volleyball and had the highest number of cases treated with surgery and a longer average withdrawal time. More studies are needed to create a larger database in order to schedule preventive measures for amateur athletes. Level IV of Evidence, Epidemiological Study.

Keywords: Athletic injuries. Knee. Ankle. Epidemiology.

Citation: Rosa BB, Asperti AM, Helito CP, Demange MK, Fernandes TL, Hernandez AJ. Epidemiology of sports injuries on collegiate athletes at a single center. Acta Ortop Bras. [online]. 2014;22(6):321-4. Available from URL: http://www.scielo.br/aob.

\section{INTRODUCTION}

University sports in Brazil do not have the expression observed in other countries such as the USA, ${ }^{1,2}$ in which the participation of athletes in universities is linked to scholarships and the professionalization of the sports career is a reality.

The Faculdade de Medicina da Universidade de São Paulo (FMUSP), São Paulo, SP, Brazil, has an athletic association (AAAOC) structured for the practice of intercollegiate sports, including skilled professionals as coaches and trainers. The frequency of training is daily and students are exposed to injuries such as ligament ruptures and fractures. ${ }^{1-3}$ One of the risk factors for such events is the fact that most of these athletes did not previously practiced sports with the above mentioned frequency, often not being adequately fit. ${ }^{4,5}$

More than 100 college students a year enter in the Athletic Association and these athletes train on average 10 hours per week, in addition to matches. They participate in local, state and national competitions by, on average, 6 to 10 years, while in medical school.

In the USA, there is a control of the types and distribution of injuries in college sports. At the "American National College
Association" (NCAA), the control is done since 1982. 2,6 Such information is useful to promote prevention strategies in sport, such as specific strengthening training, muscle strengthening and physiotherapy. ${ }^{7-13}$ In Brazil, up to now, there are no studies showing the profile of injuries at university sports, hindering prevention strategies. Therefore, the aim of this study was to assess the epidemiological evolution of these injuries in the university environment of FMUSP in the last 20 years and identify key predictors of injuries.

\section{METHODS}

Eight hundred and thirty seven college athletes, of both genders, who participated in sports in the last 20 years at FMUSP were selected.

The sports categories included in this research were: futsal, handball, women's basketball and volleyball, softball, athletics, soccer, rugby, water polo, martial arts (judo and karate), handball, basketball and volleyball.

We used a brief version of the questionnaire "Injury Surveillance System" (ISS) 2 in which information from the site of injury, mechanism of injury, year of injury and sport practiced were collected.

Todos os autores declaram não haver nenhum potencial conflito de interesses referente a este artigo.

1. Institute of Orthopedics and Traumatology, Faculdade de Medicina da Universidade de São Paulo (FMUSP), São Paulo, SP, Brasil.

Work developed at the Laboratory of Medical Investigation of the Musculoskeletal System, Department of Orthopedics and Traumatology, Faculdade de Medicina da Universidade de São Paulo (FMUSP), São Paulo, SP, Brasil.

Correspondence: Rua Dr. Ovidio Pires de Campos, 333, Cerqueira Cesar, 05403-010 São Paulo, SP, Brasil. bruno.berbert.rosa@gmail.com 
The athletes were also asked regarding the type of treatment, surgical or conservative and the time of withdrawal from sports. The withdrawal time was calculated in weeks. Respondents were asked about the use of information and all of them authorized the publication of the data.

\section{Statistical analysis}

Demographic analysis with graphs and tables of injury prevalence by gender, age, site of injury and sport were held. We also analyzed the average time of withdrawal of athletes, whether they returned to sports practice and showed new injuries.

\section{RESULTS}

Figure 1 shows the flowchart of the cases included in the survey used for the statistical analysis, where 837 athletes were surveyed, $69.89 \%$ answered the questionnaire (585) and $49.91 \%$ had sports injuries (292).

Among men, $49.1 \%$ (165) of the athletes had injuries. The percentage among women was $51 \%$ (127), which shows the similarity in injury incidence between both genders.

The most common injury was to the anterior cruciate ligament $(\mathrm{ACL})$, followed by the ankle ligament injury, which together represent $25 \%$ of cases. Only severe ligament injuries of the ankle were included, with time of withdrawal greater than 14 days. Injuries in descending order (i.e.: fractures of fingers, stress fracture of the tibia and glenohumeral dislocation) are presented in Table 1.

Among the categories studied, the ACL injury was more prevalent in women's handball, followed by men's volleyball. The ankle ligament injury was more common in volleyball, being more frequent in women than in men, as shown in Table 2.

The ACL injury alone occurred in 37 of the 585 athletes of the study, or $6.3 \%$ of the total. The incidence in women was slightly higher, with 18 cases in 249 of athletes or $7.2 \%$. In men, there were 19 injuries in 336 athletes or 5.6\%.

Analyzing the site of injury, $55.8 \%$ of injuries were in the lower limbs, especially in athletics and football (88.6\% and $78.8 \%$ respectively). Injuries to the upper limb, although less prevalent in general, were more common in water polo $(100 \%)$

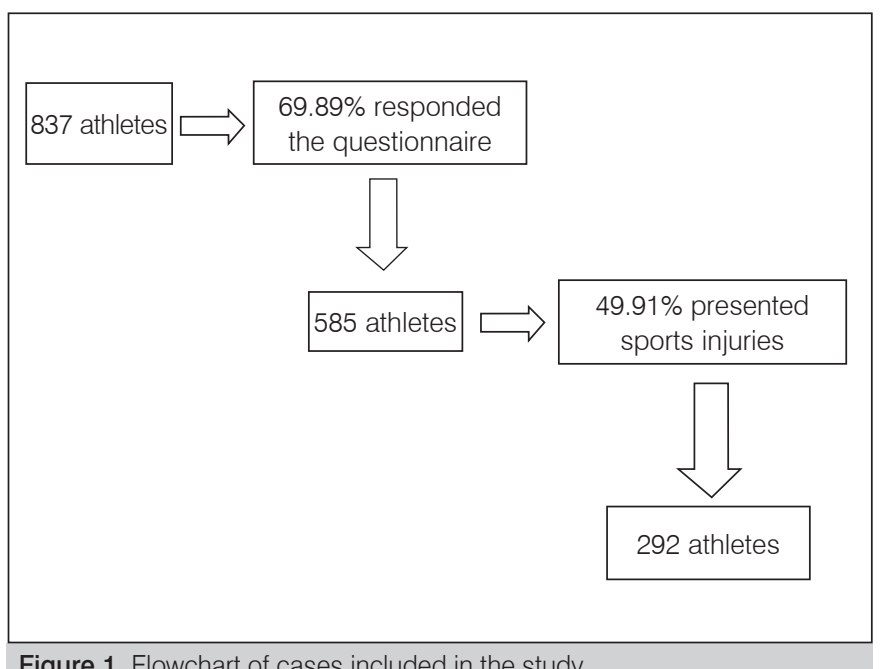

Figure 1. Flowchart of cases included in the study. and softball (75\%). Table 3 shows the division by site and type of injury.

Regarding the type of treatment, the vast majority of cases (72.9\%) were treated conservatively. A sport in which injuries resulted in greater number of surgical treatments was men's volleyball, with $56.3 \%$ of cases. In all other categories, conservative treatment was more frequent than surgical. In athletics, only $5.3 \%$ of the cases resulted in surgery.

The sport with the longest withdrawal time was the men's volleyball, with an average of 16 weeks. In general, the average withdrawal time was 11 weeks, including conservative and surgical treatments. There is a direct relationship between the time of withdrawal and the type of treatment and in injuries treated surgically, the time off was higher, approximately 21 weeks. Nine cases left sports practice after injury. (Figures 2 and 3 )

\begin{tabular}{c|c|c}
\hline \multicolumn{3}{c|}{ Table 1. Incidence of most frequent injuries. } \\
\hline Injury & Frequency (n) & Incidence \\
\hline Anterior cruciate ligament & 37 & $12.7 \%$ \\
\hline Ankle ligament injury & 36 & $12.3 \%$ \\
\hline Fractures of fingers & 26 & $8.9 \%$ \\
\hline Stress fracture of the tibia & 18 & $6.2 \%$ \\
\hline Glenohumeral dislocation & 16 & $4.8 \%$ \\
\hline Others & 161 & $48.6 \%$ \\
\hline
\end{tabular}

$\mathrm{n}=$ number of events

Table 2. Incidence of anterior cruciate ligament and ankle ligament injury at sports.

\begin{tabular}{c|c|c}
\hline Sport & ACL injury (n) & Ankle ligament injury (n) \\
\hline Women's Handball & $16 \%(8)$ & $8 \%(4)$ \\
\hline Men's Volleyball & $12.5 \%(4)$ & $12.5 \%(4)$ \\
\hline Women's Volleyball & $9.09 \%(4)$ & $13.6 \%(6)$ \\
\hline Soccer & $6.25 \%(5)$ & $6.25 \%(5)$ \\
\hline Women's basketball & $4.41 \%(3)$ & $5.88 \%(4)$ \\
\hline Men's Handball & $4.61 \%(3)$ & $6.15 \%(4)$ \\
\hline
\end{tabular}

$\mathrm{n}=$ number of events

\section{DISCUSSION}

The study shows a representative demographic pattern of injuries in the national university sports. The most important result of this study was the high incidence of serious injuries in college athletes, with time off greater than 10 days. ${ }^{2,14}$ Half of the 


\begin{tabular}{c|c} 
Table 3. Injury location and sports category. \\
\hline Category & Upper limbs (n) \\
\hline Water polo & $100 \%(6)$ \\
\hline Softball & $75 \%(9)$ \\
\hline Martial Arts & $73.7 \%(14)$ \\
\hline Rugby & $68.4 \%(13)$ \\
\hline Men's Basketball & $57.9 \%(11)$ \\
\hline Category & Lower limbs (n) \\
\hline Athletics & $88.6 \%(31)$ \\
\hline Soccer & $78.8 \%(26)$ \\
\hline Women's basketball & $77.8 \%(14)$ \\
\hline Women's Futsal & $76 \%(19)$ \\
\hline Women's Handball & $66.7 \%(16)$ \\
\hline
\end{tabular}

$\mathrm{n}=$ number of events

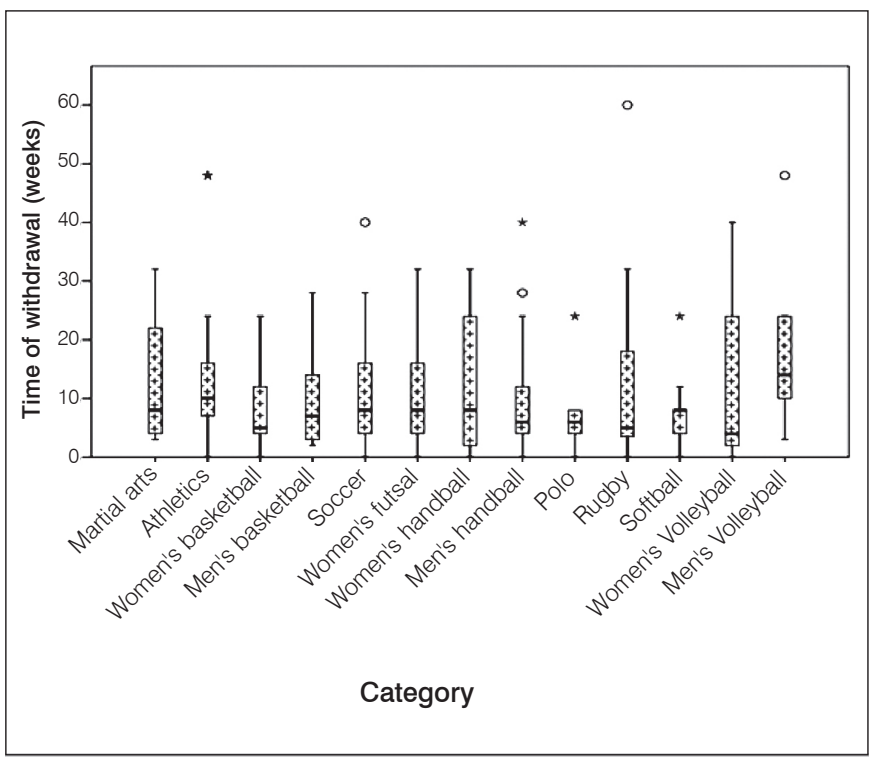

Figure 2. Withdrawal from sports in weeks.

athletes studied had at least one injury with this feature. This number indicates that college sports practice has a significant impact on the lives of college students, which reinforces the need to schedule preventive measures.

The fact that many athletes did not perform sports activities or performed non-competitive sports activities before entering college can be a risk factor for new injuries, as these athletes do not have adequate pre muscular work nor education and training base to support the high training frequency. ${ }^{4}$

The results are in agreement with the studies of Van Mechelen

Acta Ortop Bras. 2014;22(6):321-4

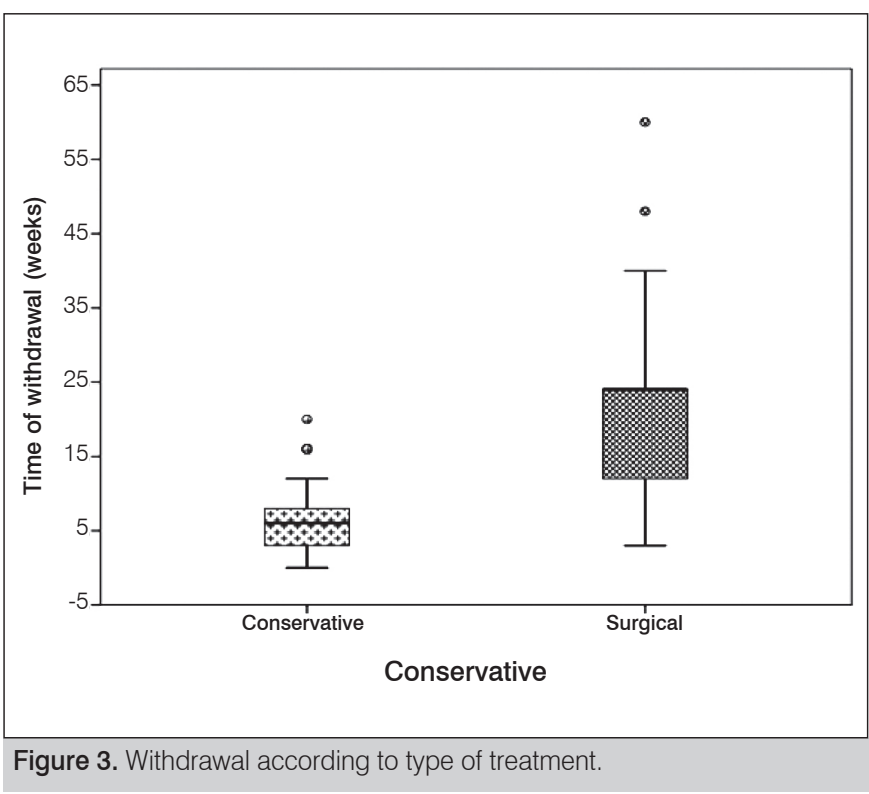

et al..$^{14}$ and Hootman et al..$^{5}$, in which the ACL injury and ligament injury of the ankle are the most frequent injuries in college sports. The relationship with the most affected sports is also true, and volleyball is the sport category in which these lesions are more frequentes. ${ }^{15}$

The injury with greater impact on the lives of the college athletes remains the ACL, with the largest number of surgical treatments and time off. Van Mechelen et al. ${ }^{14}$ and Hootman et al. ${ }^{5}$ also described a higher prevalence of these injuries in the female audience. Systematic reviews and meta-analyzes also demonstrate higher prevalence in the feminine gender. ${ }^{15,16}$

The results presented in specific sports categories such as athletics and water polo show that the type of training and exercise are directly related to injuries. In water polo, for example, there is a high prevalence of injuries in the upper limbs due to pitch and dispute for the ball with the hands. However, in athletics, because of the high intensity of training, there is a high prevalence of stress fractures. In court sports, due to jumping and cutting movements, there is a high prevalence of sprains in the lower limbs.

By not having a basis of previous data on the epidemiology of injuries in college sports, it has been difficult defining prevention strategies for each sports category. ${ }^{1}$ We observed that the creation of a national system for data collection, such as in the USA, ${ }^{2,17}$ shall facilitate the design of preventive measures in order to reduce the incidence of injuries and the withdrawal time of these athletes.

A methodological limitation of this study is its retrospective nature, in which that in order to answer the questionnaire participants rely on their memories, which can lead to recollection bias. Minor injuries can be forgotten and not mentioned.

\section{CONCLUSION}

Future studies are being conducted in a prospective manner in order to improve the quality of information and create a solid database. The clinical relevance of this study is, therefore, to present demographic information of major injuries in college sports, allowing proposing strategies for injury prevention and health promotion. 


\section{REFERENCES}

1. Adirim TA, Cheng TL. Overview of injuries in the young athlete. Sports Med. 2003;33(1):75-81.

2. Dick R, Agel J, Marshall SW. National Collegiate Athletic Association Injury Surveillance System commentaries: introduction and methods. J Athl Train. 2007;42(2):173-82.

3. Collins M, Lovell MR, Iverson GL, Ide T, Maroon J. Examining concussion rates and return to play in high school football players wearing newer helmet technology: a three-year prospective cohort study. Neurosurgery. 2006;58(2):275-86.

4. Emery CA. Risk factors for injury in child and adolescent sport: a systematic review of the literature. Clin J Sport Med. 2003;13(4):256-68.

5. Hootman JM, Dick R, Agel J. Epidemiology of collegiate injuries for 15 sports: summary and recommendations for injury prevention initiatives. J Athl Train. 2007;42(2):311-9.

6. Lohmander LS, Englund PM, Dahl LL, Roos EM. The long-term consequence of anterior cruciate ligament and meniscus injuries: osteoarthritis. Am J Sports Med. 2007;35(10):1756-69.

7. Mandelbaum BR, Silvers HJ, Watanabe DS, Knarr JF, Thomas SD, Griffin LY, et al. Effectiveness of a neuromuscular and proprioceptive training program in preventing anterior cruciate ligament injuries in female athletes: 2-year follow-up. Am J Sports Med. 2005;33(7):1003-10.

8. McGuine TA, Keene JS. The effect of a balance training program on the risk of ankle sprains in high school athletes. Am J Sports Med. 2006;34(7):1103-11.

9. Olsen OE, Myklebust G, Engebretsen L, Holme I, Bahr R. Exercises to prevent lower limb injuries in youth sports: cluster randomised controlled trial. BMJ. 2005;330(7489):449.
10. Thelen DG, Chumanov ES, Sherry MA, Heiderscheit BC. Neuromusculoskeletal models provide insights into the mechanisms and rehabilitation of hamstring strains. Exerc Sport Sci Rev. 2006;34(3):135-41.

11. Verhagen E, van der Beek A, Twisk J, Bouter L, Bahr R, van Mechelen W. The effect of a proprioceptive balance board training program for the prevention of ankle sprains: a prospective controlled trial. Am J Sports Med. 2004;32(6):1385-93.

12. Agel J, Arendt EA, Bershadsky B. Anterior cruciate ligament injury in national collegiate athletic association basketball and soccer: a 13-year review. Am J Sports Med. 2005;33(4):524-30.

13. Agel J, Evans TA, Dick R, Putukian M, Marshall SW. Descriptive epidemiology of collegiate men's soccer injuries: National Collegiate Athletic Association Injury Surveillance System, 1988-1989 through 2002-2003. J Athl Train 2007;42(2):270-7.

14. van Mechelen W, Hlobil H, Kemper HC. Incidence, severity, aetiology and prevention of sports injuries. A review of concepts. Sports Med. 1992;14(2):82-99.

15. Prodromos CC, Han Y, Rogowski J, Joyce B, Shi K. A meta-analysis of the incidence of anterior cruciate ligament tears as a function of gender, sport, and a knee injury-reduction regimen. Arthroscopy. 2007;23(12):1320-1325.e6.

16. Moses B, Orchard J, Orchard J. Systematic review: annual incidence of ACL injury and surgery in various populations. Res Sports Med. 2012;20(3-4):157-79.

17. Timpka T, Alonso JM, Jacobsson J, Junge A, Branco P, Clarsen B, et al. Injury and illness definitions and data collection procedures for use in epidemiological studies in Athletics (track and field): consensus statement. Br J Sports Med. 2014;48(7):483-90. 